\title{
Application of Unmanned Aerial Systems in Crop Production as an Aspect of Digitalization of the Agro-Industrial Complex
}

\author{
Artyom Spiridonov* \\ Federal Scientific Agroengineering Center VIM, 109428 Moscow, Russia
}

\begin{abstract}
In this article the authors provide an economic assessment of the technology of using unmanned aircraft systems in digital agriculture and justify the optimal requirements for its main technological parameters. As a measure of comparative evaluation of various options for implementing the system, an estimate of the cost of performing the technological process of using pesticides, fertilizers and other agrochemicals in conditional price units is proposed. A multi-factor experiment was carried out and variants of a mathematical model describing the relationship between agrotechnological factors and the final resultant, expressed in the conditional cost of processing $1 \mathrm{Ha}$ of agricultural land, were obtained. The optimal values of the parameters are obtained for various variants of fixing factors at the specified levels. The influence of the most significant agrotechnological factors on the cost of the technological process of using pesticides, fertilizers and other agrochemicals is shown. The values of factors that should be used in the development of new types of unmanned aerial vehicles to ensure their maximum demand in agriculture and economic efficiency are proposed.
\end{abstract}

\section{Introduction}

The Digital agriculture project aims to transform agriculture into a high-tech industry that provides the Russian population with high-quality food through the implementation of new innovative developments.

The objective possibility of implementing precision farming systems, which is part of digital agriculture, has appeared in recent years due to the creation of global positioning systems, geoinformation systems, automated control systems for agricultural technological processes, the availability of software that allows processing and analysing the information received and creating electronic maps-tasks for performing the technological process of differentiated fertilization and pesticides.

One of the main subject tasks of the transformation of Russian agriculture for 20192021 is the development of domestic equipment for differentiated application of fertilizers and plant protection products for the digital farming system [1-3].

\footnotetext{
*Corresponding author: artyom-spiridonov@yandex.ru
} 
In recent decades, due to the success in the field of microelectronics, precision mechanics, computer technology, adaptive control systems, a new direction in science and production has been widely developed all over the world - the creation of unmanned aerial vehicles, which are now widely used in agriculture due to the introduction of precision farming systems. According to various forecasts, the annual growth of the precision agriculture market is estimated at an average of $16 \%$, by 2025 the market volume should be about 10.23 billion. $\$[4-8]$.

At the same time, despite the widespread use of precision farming in the developed countries of the world, differentiated application of fertilizers and pesticides is carried out by ground equipment [9-12]. Equipment for light aircraft for differentiated application of mineral fertilizers and pesticides is under design decisions.

In this regard, research aimed at developing a technology for differentiated application of fertilizers and pesticides using helicopter-type unmanned aerial vehicles is relevant.

According to various estimates, the need for aviation and chemical works in Russia as a whole may range from 13 to 23 million hectares, on which it is necessary to perform processing.

New technologies for differentiated application of pesticides, fertilizers and other agrochemicals in precision agriculture include unmanned aerial systems (UAS) with unmanned aerial vehicles (UAVS) for monitoring fields and obtaining preliminary information on agrocenoses, unmanned aircraft (UAVs) for applying pesticides, fertilizers and other agrochemicals, ground transport and refueling complex (TPC) for transporting UAVs, refueling with fuel and working fluid, and flight control and management.

At the same time, the mobility of the UAS complex and its functionality are directly proportional to the economic efficiency of its use in agricultural production when performing aerial-chemical works.

\section{Materials and Methods}

The research was conducted using well-known methods of planning and execution of multifactorial experiments. A three-factor experiment was used as the main research tool.

Variable factors:

- working width, $\mathrm{m}, X_{1}$;

- payload, kg, $X_{2}$;

- operating speed, $\mathrm{km} / \mathrm{h}, X_{3}$.

The outcome parameter is the cost price of performing the technological process of processing $1 \mathrm{Ha}$, expressed in conventional units. One conventional unit was assumed to be equal to 0.013 US dollars to provide a more adequate valuation of the technology in relation to the CIS countries.

The natural values of the factors and their variation intervals are shown in table 1 . The plan for conducting a multi-factor experiment is shown in table 2 .

Table 1. The factors and their variation intervals

\begin{tabular}{|c|c|c|c|c|c|}
\hline & $\begin{array}{c}\text { Lower Level } \\
(-\mathbf{1})\end{array}$ & $\begin{array}{c}\text { Base Level } \\
(\mathbf{0})\end{array}$ & $\begin{array}{c}\text { High Level } \\
(+\mathbf{1})\end{array}$ & $\begin{array}{c}\text { Variation } \\
\text { Range }\end{array}$ & Name of the factor \\
\hline x1: & 5 & 7,5 & 10 & 2,5 & Working width, $\mathrm{m}$ \\
\hline x2: & 100 & 550 & 1000 & 450 & Payload, $\mathrm{kg}$ \\
\hline $\mathrm{x} 3:$ & 20 & 70 & 120 & 50 & Operating speed, $\mathrm{km} / \mathrm{h}$ \\
\hline
\end{tabular}


Table 2. Experiment plan and outcome parameters of experiments

\begin{tabular}{|c|c|c|c|c|c|c|c|}
\hline \multirow{2}{*}{$\begin{array}{c}\text { Experi } \\
\text { ment } \\
\text { numbe } \\
\mathbf{r}(\mathbf{u})\end{array}$} & \multicolumn{3}{|l|}{ The planning matrix } & \multicolumn{3}{|c|}{ Natural values of variables } & $\begin{array}{c}\text { Outcome } \\
\text { parameter } \\
\text { cost } \\
\text { price, } \\
\text { cu.) }\end{array}$ \\
\cline { 2 - 8 } & $\mathbf{x 1}$ & $\mathbf{x 2}$ & $\mathbf{x} 2$ & $\begin{array}{c}\text { Workin } \\
\text { g width, } \\
\mathrm{m}\end{array}$ & $\begin{array}{c}\text { Payloa } \\
\mathrm{d}, \mathrm{kg}\end{array}$ & $\begin{array}{c}\text { Operating } \\
\text { speed, } \\
\mathrm{km} / \mathrm{h}\end{array}$ & $\mathbf{y}(\mathbf{u})$ \\
\hline 1 & -1 & -1 & -1 & 5 & 100 & 20 & 1107,9 \\
\hline 2 & +1 & -1 & -1 & 10 & 100 & 20 & 771,6 \\
\hline 3 & -1 & +1 & -1 & 5 & 1000 & 20 & 1047 \\
\hline 4 & -1 & -1 & +1 & 5 & 100 & 120 & 562 \\
\hline 5 & -1 & 0,19 & 0,19 & 5 & 635,5 & 79,5 & 560,6 \\
\hline 6 & 0,19 & -1 & 0,19 & 7,975 & 100 & 79,5 & 549,6 \\
\hline 7 & 0,19 & 0,19 & -1 & 7,975 & 635,5 & 20 & 799,9 \\
\hline 8 & $-0,29$ & +1 & +1 & 6,775 & 1000 & 120 & 467,9 \\
\hline 9 & +1 & $-0,29$ & +1 & 10 & 419,5 & 120 & 447,1 \\
\hline 10 & +1 & +1 & $-0,29$ & 10 & 1000 & 55,5 & 562,1 \\
\hline
\end{tabular}

\section{Results and Discussion}

As a result of processing the experimental data, the equation of the mathematical model was obtained. The coefficients of the mathematical model equation are shown in table 3.the Value of the student's criterion for each coefficient and its significance are shown in table 4.

Table 3. Coefficients of the mathematical model equation

\begin{tabular}{|c|c|c|c|c|}
\hline b0 & b1 & b2 & b3 & b11 \\
\hline 507,753 & $-82,686$ & $-21,895$ & $-204,433$ & 23,189 \\
\hline b12 & b13 & b22 & b23 & b33 \\
\hline 13,203 & 72,565 & 68,664 & $-4,048$ & 116,453 \\
\hline
\end{tabular}

The equation of the mathematical model:

$y=(507,753)+(-82,686) * x 1+(-21,895) * x 2+(-$

$204,433) * x 3+(23,189) * x 1^{\wedge} 2+(68,664) * x 2^{\wedge} 2+(116,453) * x 3^{\wedge} 2+(13,203) * x 1^{*} * x 2+(72,565) *$

$x 1 * x 3+(-4,048) * x 2 * x 3$

Conclusion on the adequacy of the mathematical model: according to the Fisher criterion, the equation of the mathematical model is adequate. The model is applicable for solving production tasks.

As a constant factor, it is accepted: $\mathrm{x} 2=0$ (550).

The transformed equation of a mathematical model with a constant factor:

$y=(507,753)+(-82,686) * x 1+(0)+(-$

$204,433) * x 3+(23,189) * x 1^{\wedge} 2+(0)+(116,453) * x 3^{\wedge} 2+(0) * x 1+(72,565) * x 1 * x 3+(0) * x 3$

The occurrence of an extremum of the response function: the extremum of the response function is within the range of variable factors.

The extremum value is $\mathrm{Y}$ opt $=410,445$. The extremum of the response function corresponds to the values of the factors: $\mathrm{x} 1=0,799(9,498)$ and $\mathrm{x} 3=0,629(101,45)$ for $\mathrm{x} 2=0$ (550).

As a constant factor, it is accepted: $\mathrm{x} 3=1(120)$.

The transformed equation of a mathematical model with a constant factor:

$y=(507,753)+(-82,686) * x 1+(-21,895) * x 2+(-$

$204,433)+(23,189) * x 1^{\wedge} 2+(68,664) * x 2^{\wedge} 2+(116,453)+(13,203) * x 1 * x 2+(72,565) * x 1+(-$

$4,048) * x 2$ 
The extremum of the response function is within the range of variable factors.

The extremum value is $Y o p t=416,678$. The extremum value of the response function corresponds to the values of the factors: $\mathrm{x} 1=0,169(7,922)$ and $\mathrm{x} 2=0,173(627,85)$ for $\mathrm{x} 3=1$ (120).

As a constant factor, it is accepted: $\mathrm{x} 1=1(10)$.

The transformed equation of a mathematical model with a constant factor:

$y=(507,753)+(-82,686)+(-21,895) * x 2+(-$

$204,433) * x 3+(23,189)+(68,664) * x 2^{\wedge} 2+(116,453) * x 3^{\wedge} 2+(13,203) * x 2+(72,565) * x 3+(-$ $4,048) * x 2 * x 3$

The occurrence of an extremum of the response function: the extremum of the response function is within the range of variable factors.

The extremum value is $\mathrm{Y}$ opt $=410,486$. The extremum of the response function corresponds to the values of the factors: $\mathrm{x} 2=0,08(586)$ and $\mathrm{x} 3=0,568(98,4)$ for $\mathrm{x} 1=1(10)$. (Table 5).

Table 5. Extremum of response function

\begin{tabular}{|c|c|c|c|}
\hline $\begin{array}{c}\text { Extremum of } \\
\text { response function }\end{array}$ & Working width, $\mathrm{m}$ & Payload, kg & $\begin{array}{c}\text { Operating speed, } \\
\mathrm{km} / \mathrm{h}\end{array}$ \\
\hline $\mathrm{Y} \_$opt $=410,445$ & $\mathrm{x} 1=0,799(9,498)$ & $\mathrm{x} 2=0(550)$ & $\mathrm{x} 3=0,629(101,45)$ \\
\hline $\mathrm{Y} \_\mathrm{opt}=416,678$ & $\mathrm{x} 1=0,169(7,922)$ & $\mathrm{x} 2=0,173(627,85)$ & $\mathrm{x} 3=1(120)$ \\
\hline Y_opt $=410,486$ & $\mathrm{x} 1=0(10)$ & $\mathrm{x} 2=0,08(586)$ & $\mathrm{x} 3=0,568(98,4)$ \\
\hline
\end{tabular}

The extremum of the response function is within the range of variable factors (figure 1).

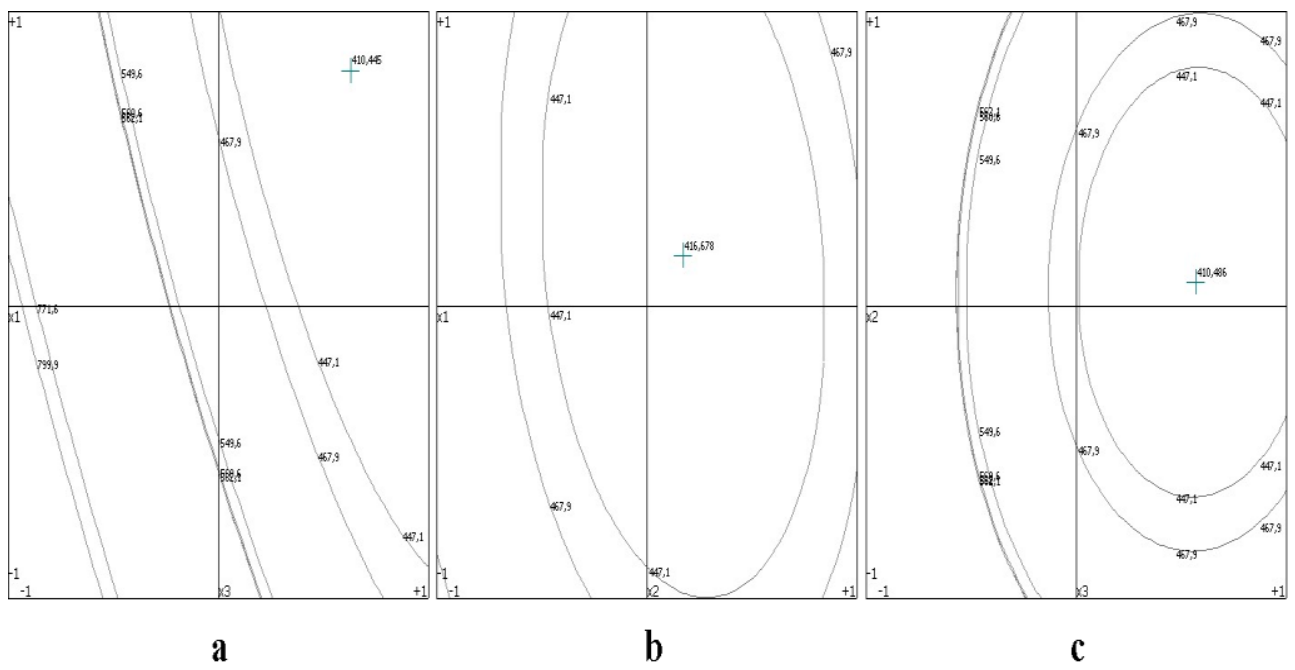

Fig. 1. The extremum of the response function is within the range of variable factors.

\section{Conclusion}

Experimental studies show the following regularities:

1. The greatest economic benefit will be achieved using the following technological parameters: working width $(\mathrm{x} 1)=9,5 \mathrm{~m}$, payload $(\mathrm{x} 2)=550 \mathrm{~kg}$, operating speed $(\mathrm{x} 3)=101$ $\mathrm{km} / \mathrm{h}$.

2. The most significant effect on the cost of process execution is working width ( $\mathrm{x} 1$ and operating speed (x3). 
3. The obtained mathematical models describing the interrelation of factors are only fair in the first approximation. To obtain more detailed and accurate dependencies, more factors need to be analyzed.

\section{References}

1. L.A. Marchenko, M.V. Myzin, I.V. Kuznetsov, T.V. Mochkova, A.Yu. Spiridonov, Agricultural Machinery and Technologies, 14(1), 61 (2020)

2. I.G. Smirnov, L.A. Marchenko, G.I. Lichman, T.V. Mochkova, A.Yu. Spiridonov, Agricultural Machinery and Technologies, 3, 10 (2017)

3. L.A. Marchenko, A.A. Artushin, I.S. Smirnov, T.V. Mochkova, A.Yu. Spiridonov, R.K. Kurbanov, Agricultural Machinery and Technologies,13(5), 38 (2019)

4. Research report; Australian Bureau of Agricultural and Resource Economics (ABARE) (2015)

5. Julian Roche, Agricultural economics (2019)

6. Kumar P. Naveen, \& Felix, Thomas, An Outline of Agricultural Economics (2020)

7. Andrew Barkley, Paul Barkley, Principles of Agricultural Economics (2020)

8. Will Martin, Economic Growth, Convergence and Agricultural Economics, Agricultural Economics, 50 (2019)

9. T.M Barnabas, Pelemo Jide, Bidemi Ajibola, Agricultural Economics and Extension Research Studies, 7, 86 (2020)

10. Jens Rommel, Meike Weltin, Is There a Cult of Statistical Significance in Agricultural Economics?, Applied Economic Perspectives and Policy (2020)

11. He Shanshan, Finance and Economics Focusing, 2, 53 (2020)

12. Gail Cramer, The Routledge Handbook of Agricultural Economics (2018) 